\title{
Chronic Expanding Hematoma with a t(11;19)(q13;q13) Chromosomal Translocation
}

\author{
IOANNIS PANAGOPOULOS ${ }^{1}$, LUDMILA GORUNOVA ${ }^{1}$, ILYÁ KOSTOLOMOV ${ }^{2}$, \\ INGVILD LOBMAIER ${ }^{3}$, BODIL BJERKEHAGEN ${ }^{3,4,5}$ and SVERRE HEIM ${ }^{1,4}$ \\ ${ }^{1}$ Section for Cancer Cytogenetics, Institute for Cancer Genetics and Informatics, \\ The Norwegian Radium Hospital, Oslo University Hospital, Oslo, Norway; \\ ${ }^{2}$ Section for Applied Informatics, Institute for Cancer Genetics and Informatics, \\ The Norwegian Radium Hospital, Oslo University Hospital, Oslo, Norway; \\ ${ }^{3}$ Department of Pathology, The Norwegian Radium Hospital, Oslo University Hospital, Oslo, Norway; \\ ${ }^{4}$ Institute of Clinical Medicine, Faculty of Medicine, University of Oslo, Oslo, Norway; \\ ${ }^{5}$ Institute of Oral Biology, Faculty of Dentistry, University of Oslo, Oslo, Norway
}

\begin{abstract}
Background/Aim: Chronic expanding hematoma is defined as a hematoma that gradually expands over 1 month or longer, is without neoplastic features on histological sections, and does not occur in the setting of coagulopathy. The pathogenetic mechanism behind its development is unknown, nor is anything known about its genetic features. Case Report: A 49-year-old man noted a tender lump close to the right femoral trochanter. Examination of a core needle biopsy showed a fibrous capsule with fibrinoid material on one side. The patient underwent surgery with removal of a cystic, encapsulated structure with central bleeding and proliferating vessels in the fibrous capsule. The reactive fibroblasts were without any sign of atypia. Genetic analyses were performed on this chronic expanding hematoma. Results: G-Banding analysis of short-term cultured cells from the chronic expanding hematoma yielded a karyotype with a single clonal chromosome abnormality: $46, X Y, t(11 ; 19)(q 13 ; q 13)[8] / 46, X Y[10] . \quad R N A$ sequencing and examination of the sequencing data using five different programs did not identify fusion genes related to the translocation. Conclusion: The acquired translocation $t(11 ; 19)(q 13 ; q 13)$ suggested that chronic expanding hematoma is a neoplastic lesion. Since the translocation did not lead to
\end{abstract}

This article is freely accessible online.

Correspondence to: Ioannis Panagopoulos, Section for Cancer Cytogenetics, Institute for Cancer Genetics and Informatics, The Norwegian Radium Hospital, Oslo University Hospital, Montebello, PO Box 4954 Nydalen, NO-0424 Oslo, Norway. Tel: +47 22782362, e-mail: ioannis.panagopoulos@rr-research.no

Key Words: Chronic expanding hematoma, cytogenetics, chromosome translocation. any fusion genes, one can speculate that it causes deregulation of gene expression.

Chronic expanding hematoma is defined as a hematoma that gradually expands over a period of 1 month or longer, does not have any neoplastic feature changes on histological sections, and does not occur in the setting of coagulopathy (1). The lesion was first reported by Friedlander and Bump in 1968 (2) and was later (1980) described as an uncommon clinicopathological entity (3). Other terms used to describe the same lesion are ancient hematoma, calcific myonecrosis, and post-traumatic cyst of soft tissues $(4,5)$. Chronic expanding hematoma may be misdiagnosed as a malignant tumor or soft tissue (1, 6-12). The pathogenetic mechanism behind the development of chronic expanding hematoma is unknown (11) and nothing is known about its cytogenetic and molecular genetic features. We present a case of chronic expanding hematoma on which genetic analyses were performed.

Ethics statement. The study was approved by the regional Ethics Committee (Regional komité for medisinsk forskningsetikk SørØst, Norge, http://helseforskning. etikkom.no). Written-informed consent was obtained from the patient to publication of the case details. The Ethics Committee's approval included a review of the consent procedure. All patient information has been deidentified.

\section{Case Report}

A 49-year-old man noticed a tender lump close to the right femoral trochanter which hurt under pressure. No known trauma was known at this specific site, but the patient had been a wrestler and so had experienced multiple traumas over the years. Examination of a core needle biopsy showed 

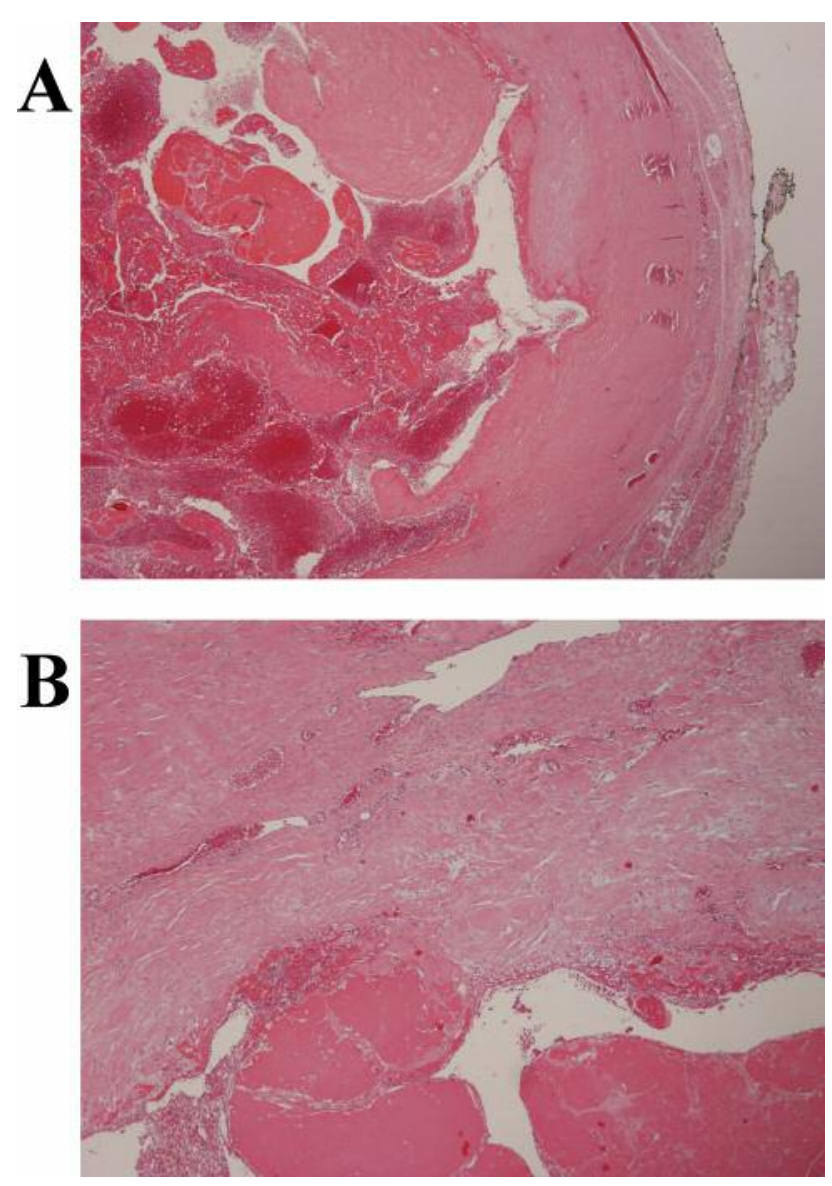

Figure 1. Microscopic picture of the chronic expanding hematoma Hematoxylin and eosin-stained section showing cystic lesion with a thick, fibrous capsule with reactive fibroblasts and proliferation of small vessels. In the center of the lesion there was blood. Magnification A: $\times 10 \mathrm{~B}: \times 20$

a fibrous capsule with fibrinoid material on one side. He underwent surgery with removal of a cystic, encapsulated structure with central bleeding and proliferating vessels in the fibrous capsule. The reactive fibroblasts were without any sign of atypia (Figure 1).

Chromosome banding. Fresh tissue from the specimen was disaggregated mechanically and enzymatically with collagenase II (Worthington, Freehold, NJ, USA). The resulting cells were cultured and harvested using standard techniques (13). Chromosome preparations were G-banded with Wright's stain (Sigma-Aldrich, St Louis, MO, USA) and examined. Metaphases were analyzed and karyograms prepared using the CytoVision computer-assisted karyotyping system (Leica Biosystems, Newcastle, UK). The karyotypes were described according to the International System for Human Cytogenomic Nomenclature (14).
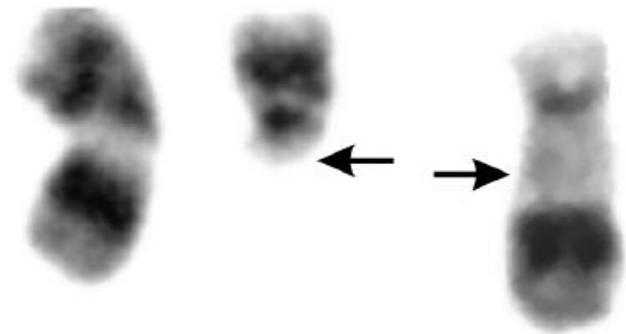

\section{$11 \operatorname{der}(11)$}

\section{$\operatorname{der}(19)$}

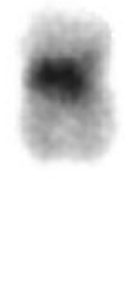

19
Figure 2. Partial karyotype showing the $\operatorname{der}(11) t(11 ; 19)(q 13 ; q 13)$, der(19)t(11;19)(q13;q13), and normal chromosomes 11 and 19. Breakpoint positions are indicated by arrows.

RNA sequencing. Total RNA was extracted from frozen $\left(-80^{\circ} \mathrm{C}\right)$ tissue adjacent to that used for cytogenetic analysis and histological examination using miRNeasy Mini Kit (Qiagen Nordic, Oslo, Norway). One microgram of total RNA was sent to the Genomics Core Facility at the Norwegian Radium Hospital, Oslo University Hospital (http://genomics.no/oslo/) for high-throughput paired-end RNA-sequencing. For library preparation, Illumina TruSeq RNA Access Library Prep kit was used (Illumina, San Diego, CA, USA; https://support.illumina.com/content/dam/illuminasupport/documents/documentation/chemistry_documentation/s amplepreps_truseq/truseqrnaaccess/truseq-rna-access-libraryprep-guide-15049525-b.pdf). Sequencing was performed on NextSeq 550 System (Illumina) and 76 million reads were generated. The software packages FusionCatcher, deFuse, ChimeraScan, TopHat-Fusion, and FuSeq were used to find fusion transcripts (15-21).

Results of analyses. G-Banding analysis of short-term cultured cells from the chronic expanding hematoma yielded a karyotype with a single clonal chromosome abnormality: 46,XY,t(11;19)(q13;q13)[8]/46,XY[10] (Figure 2). RNA sequencing and examination of the sequencing data with five different programs did not identify any fusion genes related to the translocation (data not shown).

\section{Discussion}

To the best of our knowledge, this case of chronic expanding hematoma was the first which has been examined cytogenetically and investigated molecularly for possible generation of fusion genes. The tumor had an acquired chromosomal translocation, $\mathrm{t}(11 ; 19)(\mathrm{q} 13 ; \mathrm{q} 13)$. This strongly suggests that chronic expanding hematoma is a neoplastic process and not an inflammatory response as was previously assumed $(3,22)$. However, the observed translocation did not lead to any fusion genes. 
The chromosomal translocation $\mathrm{t}(11 ; 19)(\mathrm{q} 13 ; \mathrm{q} 13)$ has also been reported as an acquired, recurrent genomic rearrangement in mesenchymal hamartoma of the liver, which is a rare benign tumor in children (23-28). Molecular studies of such tumors showed that the $\mathrm{t}(11 ; 19)(\mathrm{q} 13 ; \mathrm{q} 13)$ of mesenchymal hamartoma was associated with deregulation of gene expression (29-31). The genomic breakpoint on chromosome 19 occurred at chromosomal sub-band 19q13.42 in a $23-\mathrm{kb}$ gene-poor region (chr19:54,151,101-54173857 on human reference genome GRCh37/hg19 which was named MHLB1 (31, 32). This $M H L B 1$ locus lies within the C19MC region which is the largest human microRNA gene cluster discovered to date (33). C19MC is an approximately 100-kb long cluster which consists of 46 tandemly repeated, primate-specific pre-miRNA genes that are flanked by Alu elements and embedded within a 400- to 700nucleotide long repeated unit (chr19:54150000-54270000) (33). The $\mathrm{C} 19 \mathrm{MC}$ region is also rich in repetitive elements and $90 \%$ of the sequence in the C19MC is comprised of Alu repeats (33). Aberrant activation of $\mathrm{C} 19 \mathrm{MC}$, leading to dysregulated microRNA profiles, was thus pathogenetically implicated in mesenchymal hamartoma of the liver (29-31).

On chromosome 11, the hamartoma breakpoints were located within the metastasis associated lung adenocarcinoma transcript 1 (MALAT1) gene on chromosomal sub-band 11q13.1 (chr11:65,264,697-65,275,032). MALAT1 is a noncoding RNA which is ubiquitously expressed in almost all human tissues and plays a role in various cellular processes, such as alternative splicing and transcriptional and posttranscriptional regulation (34). Studies have shown that MALAT1 is dysregulated and plays a critical role in the development and progression of various cancer types (34-37). A recurrent MALAT1-GLI1 fusion, resulting in GLI family zinc finger 1 (GLII) overexpression, was described in gastroblastomas and plexiform fibromyxomas $(38,39)$.

In conclusion, the finding of an acquired translocation in cells cultured from a chronic expanding hematoma strongly suggests that this is a tumor that arises through a neoplastic mechanism. The fact that the same translocation, $\mathrm{t}(11 ; 19)(\mathrm{q} 13 ; \mathrm{q} 13)$, has also been seen repeatedly in mesenchymal hamartoma, another completely benign lesion, adds indirect evidence to this interpretation. Since the translocation did not lead to formation of any fusion genes, it is likely that dysregulation of gene expression is key to how this genomic alteration leads to neoplasia.

\section{Conflicts of Interest}

The Authors declare that no potential conflicts of interest exist.

\section{Authors' Contributions}

IP conceived the study, designed the analyses, evaluated the data, and drafted the article. LG performed cytogenetic analysis. IK performed bioinformatic analysis. IL and BB performed the pathological examination. SH supervised the research and assisted with writing of the article. All Authors read and approved the final article.

\section{Acknowledgements}

This work was supported by grants from Radiumhospitalets Legater.

\section{References}

1 Everhart JS, Fajolu OK and Mayerson JL: Spontaneous, chronic expanding posterior thigh hematoma mimicking soft-tissue sarcoma in a morbidly obese pregnant woman. Am J Orthop 44: E29-31, 2015. PMID: 25566562.

2 Friedlander HL and Bump RG: Chronic expanding hematoma of the calf. A case report. J Bone Joint Surg Am 50: 1237-1241, 1968. PMID: 5675406.

3 Reid JD, Kommareddi S, Lankerani M and Park MC: Chronic expanding hematomas. A clinicopathologic entity. JAMA 244: 2441-2442, 1980. PMID: 6448929.

4 Mentzel T, Goodlad JR, Smith MA and Fletcher CD: Ancient hematoma: A unifying concept for a post-traumatic lesion mimicking an aggressive soft tissue neoplasm. Mod Pathol 10: 334-340, 1997. PMID: 9110295.

5 Miettinen M: Miscellaneous tumor-liek lesions, and histiocytic and foreign body reactions. In: Modern Soft Tissue Pathology: Tumors and Non-Neoplastic Conditions. Miettinen M (ed.). New York, NY, USA: Cambridge University Press, pp. 965-981, 2010.

6 Takahama M, Yamamoto R, Nakajima R, Izumi N and Tada H: Extrathoracic protrusion of a chronic expanding hematoma in the chest mimicking a soft-tissue tumor. Gen Thorac Cardiovasc Surg 58: 202-204, 2010. PMID: 20401716. DOI: 10.1007/s11748-0090496-z

7 Okada K, Sugiyama T, Kato H and Tani T: Chronic expanding hematoma mimicking soft-tissue neoplasm. J Clin Oncol 19: 29712972, 2001. PMID: 11387374. DOI: 10.1200/JCO.2001.19.11.2971

8 Taïeb S, Penel N, Vanseymortier L and Ceugnart L: Soft-tissue sarcomas or intramuscular haematomas? Eur J Radiol 72: 44-49, 2009. PMID: 19520533. DOI: 10.1016/j.ejrad.2009.05.026

9 Niimi R, Matsumine A, Kusuzaki K, Okamura A, Matsubara T, Uchida A and Fukutome K: Soft-tissue sarcoma mimicking large haematoma: A report of two cases and review of the literature. J Orthop Surg 14: 90-95, 2006. PMID: 16598096. DOI: $10.1177 / 230949900601400120$

10 Liu PT, Leslie KO, Beauchamp CP and Cherian SF: Chronic expanding hematoma of the thigh simulating neoplasm on gadolinium-enhanced MRI. Skeletal Radiol 35: 254-257, 2006. PMID: 16283176. DOI: 10.1007/s00256-005-0042-8

11 Cebesoy O, Tutar E and Arpacioglu O: Spontaneous giant expanding thigh hematoma mimicking soft-tissue neoplasm. Joint Bone Spine 75: 64-66, 2008. PMID: 17904890. DOI: 10.1016/j.jbspin.2007.01.041

12 Sreenivas M, Nihal A and Ettles DF: Chronic haematoma or soft-tissue neoplasm? A diagnostic dilemma. Arch Orthop Trauma Surg 124: 495-497, 2004. PMID: 15248076. DOI: 10.1007/s00402-004-0698-x

13 Mandahl N: Methods in solid tumour cytogenetics. In: Human cytogenetics: malignancy and acquired abnormalities (Rooney DE ed.). New York: Oxford University Press, pp. 165-203, 2001. 
14 McGowan-Jordan J, Simons A and Schmid M: ISCN 2016: An International System for Human Cytogenomic Nomenclature. Basel: Karger, 2016.

15 Iyer MK, Chinnaiyan AM and Maher CA: ChimeraScan: a tool for identifying chimeric transcription in sequencing data. Bioinformatics 27: 2903-2904, 2011. PMID: 21840877. DOI: 10.1093/bioinformatics/btr467

16 Kangaspeska S, Hultsch S, Edgren H, Nicorici D, Murumagi A and Kallioniemi O: Reanalysis of RNA-sequencing data reveals several additional fusion genes with multiple isoforms. PLoS One 7: e48745, 2012. PMID: 23119097. DOI: 10.1371/journal.pone. 0048745

17 Kim D and Salzberg SL: TopHat-Fusion: An algorithm for discovery of novel fusion transcripts. Genome Biol 12: R72, 2011. PMID: 21835007. DOI: 10.1186/gb-2011-12-8-r72

18 McPherson A, Hormozdiari F, Zayed A, Giuliany R, Ha G, Sun MG, Griffith M, Heravi Moussavi A, Senz J, Melnyk N, Pacheco M, Marra MA, Hirst M, Nielsen TO, Sahinalp SC, Huntsman D and Shah SP: deFuse: An algorithm for gene fusion discovery in tumor RNA-Seq data. PLoS Comput Biol 7: e1001138, 2011. PMID: 21625565. DOI: 10.1371/journal.pcbi.1001138

19 Nicorici D, Satalan H, Edgren H, Kangaspeska S, Murumagi A, Kallioniemi O, Virtanen S and Kikku O: FusionCatcher - a tool for finding somatic fusion genes in paired-end RNA-sequencing data. bioRxiv, 2014. DOI: 10.1101/011650

20 Trapnell C, Pachter L and Salzberg SL: TopHat: Discovering splice junctions with RNA-Seq. Bioinformatics 25: 1105-1111, 2009. PMID: 19289445. DOI: 10.1093/bioinformatics/btp120

21 Vu TN, Deng W, Trac QT, Calza S, Hwang W and Pawitan Y: A fast detection of fusion genes from paired-end RNA-seq data. BMC Genomics 19: 786, 2018. PMID: 30382840. DOI: 10.1186/s12864-018-5156-1

22 Labadie EL and Glover D: Physiopathogenesis of subdural hematomas. Part 1: Histological and biochemical comparisons of subcutaneous hematoma in rats with subdural hematoma in man. J Neurosurg 45: 382-392, 1976. PMID: 956874. DOI: 10.3171/jns.1976.45.4.0382

23 Bove KE, Blough RI and Soukup S: Third report of $\mathrm{t}(19 \mathrm{q})(13.4)$ in mesenchymal hamartoma of liver with comments on link to embryonal sarcoma. Pediatr Dev Pathol 1: 438-442, 1998. PMID: 9688769. DOI: 10.1007/s100249900060

24 Mascarello JT and Krous HF: Second report of a translocation involving $19 \mathrm{q} 13.4$ in a mesenchymal hamartoma of the liver. Cancer Genet Cytogenet 58: 141-142, 1992. PMID: 1551077. DOI: 10.1016/0165-4608(92)90100-m

25 Murthi GV, Paterson L and Azmy A: Chromosomal translocation in mesenchymal hamartoma of liver: What is its significance? J Pediatr Surg 38: 1543-1545, 2003. PMID: 14577085. DOI: $10.1016 / \mathrm{s} 0022-3468(03) 00512-8$

26 Rakheja D, Margraf LR, Tomlinson GE and Schneider NR: Hepatic mesenchymal hamartoma with translocation involving chromosome band 19q13.4: A recurrent abnormality. Cancer Genet Cytogenet 153: 60-63, 2004. PMID: 15325096. DOI: 10.1016/j.cancergencyto.2003.12.004

27 Sharif K, Ramani P, Lochbuhler H, Grundy R and de Ville de Goyet $\mathrm{J}$ : Recurrent mesenchymal hamartoma associated with $19 \mathrm{q}$ translocation. A call for more radical surgical resection. Eur $\mathbf{J}$ Pediatr Surg 16: 64-67, 2006. PMID: 16544232 DOI: 10.1055/s2005-873072
28 Sugito K, Kawashima H, Uekusa S, Inoue M, Ikeda T and Kusafuka T: Mesenchymal hamartoma of the liver originating in the caudate lobe with $\mathrm{t}(11 ; 19)(\mathrm{q} 13 ; \mathrm{q} 13.4)$ : Report of a case. Surg Today 40: 83-87, 2010. PMID: 20037848. DOI: 10.1007/s00595009-4003-Z

29 Kapur RP, Berry JE, Tsuchiya KD and Opheim KE: Activation of the chromosome $19 q$ microRNA cluster in sporadic and androgenetic-biparental mosaicism-associated hepatic mesenchymal hamartoma. Pediatr Dev Pathol 17: 75-84, 2014. PMID: 24555441. DOI: 10.2350/13-12-1415-OA.1

30 Keller RB, Demellawy DE, Quaglia A, Finegold M and Kapur RP: Methylation status of the chromosome arm 19q MicroRNA cluster in sporadic and androgenetic-biparental mosaicismassociated hepatic mesenchymal hamartoma. Pediatr Dev Pathol 18: 218-227, 2015. PMID: 25751191. DOI: 10.2350/15-011600-OA.1

31 Mathews J, Duncavage EJ and Pfeifer JD: Characterization of translocations in mesenchymal hamartoma and undifferentiated embryonal sarcoma of the liver. Exp Mol Pathol 95: 319-324, 2013. PMID: 24120702. DOI: 10.1016/j.yexmp.2013.09.006

32 Rajaram V, Knezevich S, Bove KE, Perry A and Pfeifer JD: DNA sequence of the translocation breakpoints in undifferentiated embryonal sarcoma arising in mesenchymal hamartoma of the liver harboring the $\mathrm{t}(11 ; 19)(\mathrm{q} 11 ; \mathrm{q} 13.4)$ translocation. Genes Chromosomes Cancer 46: 508-513, 2007. PMID: 17311249 DOI: $10.1002 /$ gcc.20437

33 Bortolin-Cavaille ML, Dance M, Weber M and Cavaille J: C19MC microRNAs are processed from introns of large Pol-II, non-protein-coding transcripts. Nucleic Acids Res 37: 34643473, 2009. PMID: 19339516. DOI: 10.1093/nar/gkp205

34 Zhang X, Hamblin MH and Yin KJ: The long noncoding RNA MALAT1: Its physiological and pathophysiological functions. RNA Biol 14: 1705-1714, 2017. PMID: 28837398. DOI: 10.1080/15476286.2017.1358347

35 Liu J, Peng WX, Mo YY and Luo D: MALAT1-mediated tumorigenesis. Front Biosci 22: 66-80, 2017. PMID: 27814602.

36 Zhao M, Wang S, Li Q, Ji Q, Guo P and Liu X: MALAT1: A long non-coding RNA highly associated with human cancers. Oncol Lett 16: 19-26, 2018. PMID: 29928382. DOI: $10.3892 / \mathrm{ol} .2018 .8613$

37 Sun Y and Ma L: New Insights into Long Non-Coding RNA MALAT1 in cancer and metastasis. Cancers 11: 216, 2019. PMID: 30781877. DOI: 10.3390/cancers11020216

38 Spans L, Fletcher CD, Antonescu CR, Rouquette A, Coindre JM, Sciot $\mathrm{R}$ and Debiec-Rychter M: Recurrent MALAT1-GLII oncogenic fusion and GLII up-regulation define a subset of plexiform fibromyxoma. J Pathol 239: 335-343, 2016. PMID: 27101025. DOI: $10.1002 /$ path. 4730

39 Graham RP, Nair AA, Davila JI, Jin L, Jen J, Sukov WR, Wu TT, Appelman HD, Torres-Mora J, Perry KD, Zhang L, KloftNelson SM, Knudson RA, Greipp PT and Folpe AL: Gastroblastoma harbors a recurrent somatic MALAT1-GLI1 fusion gene. Mod Pathol 30: 1443-1452, 2017. PMID: 28731043. DOI: $10.1038 /$ modpathol.2017.68

Received November 26, 2019 Revised December 4, 2019 Accepted December 6, 2019 